\title{
Epitaxial growth of III-V nanowires on Si(111) microheaters using an environmental transmission electron microscope
}

Andersen, Christopher Røhl; Jacobsson, Daniel ; Lehmann, Sebastian ; Dick, Kimberly A.; Mølhave, Kristian

Publication date:

2020

Document Version

Peer reviewed version

Link back to DTU Orbit

Citation $(A P A)$ :

Andersen, C. R., Jacobsson, D., Lehmann, S., Dick, K. A., \& Mølhave, K. (2020). Epitaxial growth of III-V nanowires on Si(111) microheaters using an environmental transmission electron microscope. Abstract from Virtual Early Career European Microscopy Congress 2020.

\section{General rights}

Copyright and moral rights for the publications made accessible in the public portal are retained by the authors and/or other copyright owners and it is a condition of accessing publications that users recognise and abide by the legal requirements associated with these rights.

- Users may download and print one copy of any publication from the public portal for the purpose of private study or research.

- You may not further distribute the material or use it for any profit-making activity or commercial gain

- You may freely distribute the URL identifying the publication in the public portal 


\section{Epitaxial growth of III-V nanowires on $\mathrm{Si}(111)$ microheaters using an environmental transmission electron microscope}

Christopher Røhl Andersen ${ }^{1,2}$, Daniel Jacobsson ${ }^{2,3}$, Sebastian Lehmann ${ }^{3,4}$, Kimberly A. Dick ${ }^{2,3,4}$ and Kristian Mølhave ${ }^{1}$

1. National Centre for Nano Fabrication and Characterization, Technical University of Denmark, 2800 Kgs. Lyngby, Denmark

2. nCHREM and Centre for Analysis and Synthesis, Lund University, 22100 Lund, Sweden

3. NanoLund, Lund University, 22100 Lund, Sweden

4. Solid State Physics, Lund University, 22100 Lund, Sweden

Gold-catalyzed III-V nanowires are grown epitaxially on microfabricated silicon microheaters in an environmental transmission electron microscope (ETEM). The study contributes to the fundamental understanding of crystal growth at nanoscale as well as the fabrication of future microdevices. The study includes both design, fabrication and characterization of microheaters integrated into a silicon on insulator (SOI) chip suitable for specialized ETEM holders. The setup is used for in situ nucleation and growth studies of gold-catalyzed III-V nanowires at different growth parameters on the silicon microheaters, which also work as substrate with a (111) crystal orientation.

Microheaters have previously been used for epitaxial growth of silicon nanowires [1]. Observing nanowires bridging from one microheater to another in situ TEM has resulted in unique studies of contact formation [2] and electrical characterization of single nanowires [3] resulting in nanowire based microdevices. The setup has also led to important fundamental results for nanowire growth measuring the surface tension of gold-catalyzed silicon nanowires [4]. The present study extends the previous observations with an extra dimension by studying goldcatalyzed III-V nanowire growth live in a unique ETEM with a purpose built gas handling system for metal-organic vapor deposition [5].

Silicon microheaters have been fabricated based on previous designs [6]. For silicon nanowires, the growth rate can be used to determine the temperature profile of the microheaters [6], but using more complex compositions such as III-V nanowires, other methods are used to determine the temperature profile for the microheaters including simulations with COMSOL Multiphysics ${ }^{\circledR}$. Au-nanoparticles are introduced as catalyst particles using aerosol deposition. A good contact between the Au-nanoparticles and the silicon microheaters is important to get epitaxial growth. This is encouraged by annealing the microheaters on a hot plate in a nitrogen atmosphere right after gold deposition. Another important interface besides that of Au-catalyst and Si-substrate is the contact between the catalyst and the surrounding precursor gases. An oxide layer is formed on the surface of the catalyst and removing this is a part of the nucleation studies. Once the nanowires are growing, the suspended nanowire growth is investigated including the growth of crystal phase heterostructures. By changing gas flows, the crystal structure of the GaAs nanowire can be deliberately tuned from hexagonal wurtzite to cubic zincblende [7].

Microheaters prepared as described above are loaded into the ETEM. Applying a current to the device lead to resistive heating of the microheaters (figure 1a). The eutectic point of gold and silicon is found, when the gold particle forms a liquid alloy with the silicon substrate (figure $1 \mathrm{~b}$ ). 
As an AuSi liquid is formed and oxide has been removed from the catalyst surface, epitaxial growth is achieved (figure 1c), which is being confirmed by diffraction patterns (figure $1 \mathrm{~d}-\mathrm{e}$ ). The epitaxial growth is used to study the effect of changing gas flows on crystal structure as control of the changing crystal structure can allow for formation of crystal phase heterostructure (Figure 2).

In conclusion, the present study investigates the growth of gold-catalyzed III-V nanowires on resistive heated microfabricated $\mathrm{Si}(111)$ cantilevers. It demonstrates different growth behaviors of the suspended nanowires by changing growth parameters.

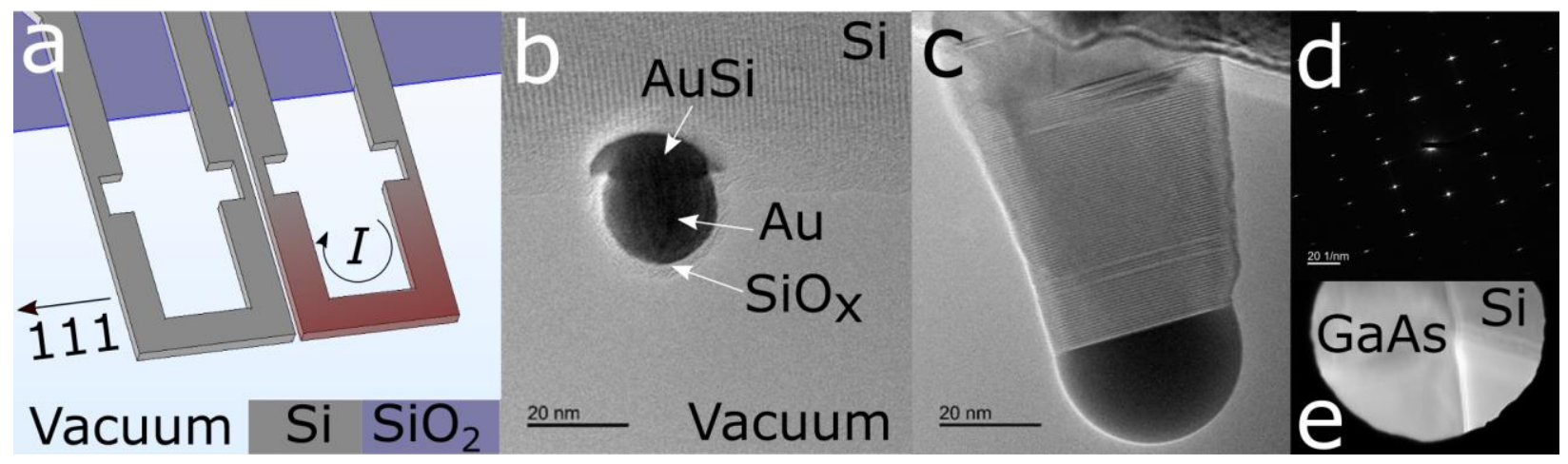

Figure 1: Silicon microheaters integrated into a silicon on insulator chip hanging into vacuum (a). Applying a current will heat up the microheaters forming a liquid AuSi alloy. TEM images of AuSi alloy achieved at temperatures above the eutectic point (b) and an epitaxially growing nanowire (c). The epitaxial growth is verified by diffraction patterns (d) of both silicon microheater and GaAs nanowire (e).

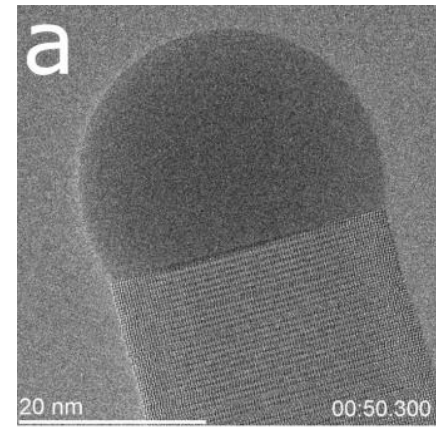

TMGa: $0.1 \mathrm{sccm}$

$\mathrm{AsH}_{3}: 1.0 \mathrm{sccm}$

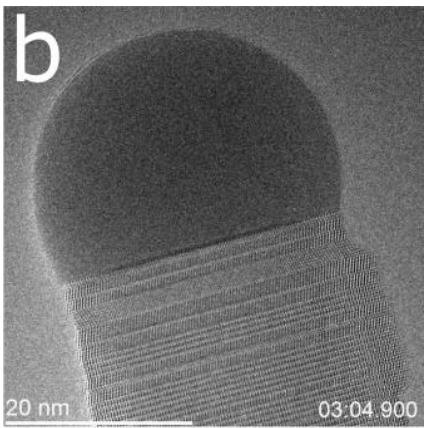

TMGa: $1.0 \mathrm{sccm}$

$\mathrm{AsH}_{3}: \mathbf{1 . 0} \mathrm{sccm}$

Figure 2: Nanowire growing at different applied gas flows from one video sequence going from wurtzite (a) structure to introducing sections with zincblende structure (b). The snapshots are taken as the nanowire grows.

References:

[1] K Mølhave, B A Wacaser, D H Petersen, J B Wagner, L Samuelson and P Bøggild, Small 4 (2008), p. 1741-6

[2] S B Alam, F Panciera, O Hansen, K Mølhave and F M Ross, Nano Lett. 15 (2015), p. 6535-41

[3] C Kallesøe, C-Y Wen, T J Booth, O Hansen, P Bøggild, F M Ross and K Mølhave , Nano Lett. 12 (2012), p. 2965-70

[4] F Panciera, M M Norton, S B Alam, S Hofmann, K Mølhave and F M Ross, Nat. Commun. 7 (2016), 
pp. 12271

[5] C Hetherington, D Jacobsson, K A Dick and R Wallenberg, Semicond. Sci. Technol 35 (2020), pp. 34004

[6] C Kallesøe, C Y Wen, K Mølhave, P Bøggild and F M Ross, Small 6 (2010), p. 2058-64

[7] D Jacobsson, F Panciera, J Tersoff, M C Reuter, S Lehmann, S Hofmann, K A Dick and F M Ross, Nature 531 (2016), p. 317-22

[8] We acknowledge financial support from DTU Nanolab, DTU Fotonik, the Knut and Alice Wallenberg Foundation (KAW), the Swedish Research Council (VR), and the Swedish Foundation for Strategic Research (SSF). 